\title{
A criança e sua relação com a interdição: a mobilização de arranjos discursivos particulares
}

Marlete Sandra Diedrich*

\section{Resumo}

Neste artigo, reflete-se sobre o caráter de interdição que marca a relação do falante com a língua, o que envolve os conceitos de cultura e sociedade. Faz-se um deslocamento da temática trabalhada por Benveniste em A blasfemia e a eufemia para se discutir como a criança vive essa relação de interdição desde muito cedo e encontra, ao longo de sua experiência, modos de lidar com ela, os quais se expressam por meio de determinados arranjos particulares no discurso.

Palauras-chave: Interdição. Experiência da criança. Arranjos.

\section{Uma contextualização inicial}

É sabido que os estudos da enunciação no Brasil alcançam um estágio de maturidade excepcional nos dias de hoje e isso tem suas devidas consequências no campo. Por essa razão, quando se faz menção aos estudos da enunciação na perspectiva benvenistiana, essa questão merece atenção especial, dada a forma como tais estudos foram se construindo no país, a chamada "recepção de Benveniste" no Brasil (FLORES, 2017, p. 77). Para Flores, a primeira recepção dos trabalhos de Benveniste ocorreu entre os anos 1960 e parte dos anos 1990, mediada por outras áreas da linguística. A segunda recepção, no entanto, ocorre mais recentemente, após a segunda metade dos anos 1990 até os dias atuais.

Docente do Programa de Pós-Graduação em Letras da Universidade de Passo Fundo. E-mail: marlete@upf.br

Data de submissão: set. 2018 - Data de aceite: out. 2018 http://dx.doi.org/10.5335/rdes.v14i3.8585 
Hoje, segundo Flores (2017), é possível se definirem três eixos que estruturam a segunda recepção de Benveniste no Brasil: o primeiro eixo situa a enunciação no centro da reflexão e justamente por isso produz uma linguística da enunciação entendida como stricto sensu. Já o segundo eixo também situa a enunciação no centro da reflexão, mas numa articulação ao conjunto da teoria da linguagem de Benveniste, o que acaba por permitir a abertura para uma teoria da linguagem que dialoga com ciências conexas. Há ainda um terceiro eixo, o qual situa a imanência da teoria da linguagem do autor no centro da reflexão, numa clara revisão de termos, noções e conceitos da teoria por ele apresentada, produzindo estudos intrateóricos, numa verdadeira hermenêutica da teoria.

Com base nessa definição, esclareço, desde já, que a discussão que apresento neste artigo se insere no segundo eixo, uma vez que tenho me dedicado a investigar a experiência da criança na linguagem numa perspectiva voltada para as questões interacionais e sociais. Encontro nos princípios benvenistianos um caminho para iluminar as discussões que tenho proposto. No caso específico deste artigo, volto-me para a relação do homem falante com a interdição imposta pela cultura de uma sociedade manifestada em seu discurso. Acredito que a criança vive essa relação desde muito cedo e encontra, ao longo de sua experiência, modos de lidar com tais interdições, os quais se expressam na língua mobilizada no discurso. Sendo assim, autorizo-me a deslocar os princípios benvenistianos para olhar a problemática da criança que tem seu dizer interditado por elementos culturais manifestados em sua vivência social, o que entendo ser uma certa abertura da teoria de Benveniste para um diálogo com a aquisição da linguagem.

Considero importante lembrar que em minha tese de doutoramento (DIEDRICH, 2015) apresento uma proposta acerca do aspecto vocal da enunciação na experiência de aquisição da linguagem vivida pela criança, segundo a qual os arranjos vocais mobilizados pela criança a cada enunciação são vistos a partir de relações de interpretância da língua com diferentes sistemas culturais que caracterizam a vida em sociedade. Acredito que tais questões nos ajudam a entender o deslocamento que estou propondo neste artigo, já que apontam para a vivência, pela criança, do que Benveniste refere como "semantismo social" (1968/1989).

Desde lá, tenho buscado, em minhas pesquisas, olhar para a linguagem da criança e sua relação com os rudimentos da sua cultura, o que tem me proporcionado incursões investigativas sobre questões que colocam no centro da discussão as relações de significância na vida social. Afinal, o que se espera de uma criança pequena que aprende uma língua é que ela se insira na vida social que a cerca; e isso só acontece na mobilização das relações significantes. Acredito que os trabalhos de Benveniste, embora não tenham focalizado tais questões de 
maneira específica, permitem, pelos conceitos e princípios que constituem suas reflexões, que pensemos na experiência da criança na linguagem como reveladoras das relações de interpretância, do semantismo social que se marca na língua, entre outras.

Por essa razão, ao trabalhar com dados naturalísticos de fala de uma criança na faixa etária de dois anos a dois anos e sete meses, vejo-me interrogada pelos fatos enunciativos por ela apresentados em sua relação com os adultos e com crianças mais velhas acerca da interdição linguística. Refiro-me a um conjunto de valores sociais e culturais que determinam o que pode e o que não pode ser dito numa dada situação, como uma espécie de convenção social que conduz o dizer da criança. Certamente, não se trata de um tema novo e sua manifestação cotidiana é bastante conhecida, principalmente via manifestação do dizer do outro, o adulto, que, por meio de determinadas fórmulas linguísticas, interdita o dizer da criança: "Não diz assim que é feio", "Não pode falar assim", entre outras tantas que circulam na sociedade.

Essa interrogação produzida pelos fatos enunciativos da criança encontra eco na discussão apresentada por Benveniste no texto A blasfemia e a eufemia (1969/1989a), o qual figura nas atas do colóquio organizado pelo Centro Internacional de Estudos Humanistas e pelo Instituto de Estudos Filosóficos de Roma, datadas de 1969. Certamente muito já se disse em relação a esse tex- to e em relação à sua produção: desde o estudo das notas preparatórias até a relação das ideias nele apresentadas com os princípios basilares do estudo da enunciação. Ao decidir revisitá-lo, no entanto, fui movida pela possibilidade de relação entre as questões apresentadas por Benveniste e a busca de respostas para a interrogação apresentada anteriormente sobre o dizer da criança que é interditado. Sendo assim, volto-me para esse texto de Benveniste no intuito de entender o que faz o falante quando diz ou quando interdita seu dizer e de que forma esse "dizer interdito" é dependente dos arranjos linguísticos mobilizados no discurso. Vejo nesse tema a possibilidade de o analista da língua, o linguista, estudar as relações da língua com a sociedade e a cultura, o que, certamente, dialoga com os estudos da linguagem da criança, a qual se constitui como sujeito do dizer via relações enunciativas estabelecidas no seio da vida social.

\section{O falante que viola uma interdição}

Com o propósito e a motivação já apresentados na seção anterior, retomo brevemente a tese apresentada por Benveniste (1969/1989a) no texto $A$ blasfemia e a eufemia.

Ao apresentar os neologismos "blasfemia" e "eufemia", o autor vê na ação conjunta das duas atividades a produção da imprecação, considerada a expressão blasfêmica por excelência. Ao blasfemar, 
o falante viola a interdição bíblica segundo a qual não se pronuncia o nome de Deus. Assim, o autor vê na imprecação um fato de linguagem que constitui sozinha uma classe de expressões típicas que o linguista em geral remete ao léxico ou à fraseologia.

Na blasfemia, o que está em jogo não é o fato de se dizer alguma coisa, emitir uma opinião, mas trata-se da ação de pronunciar um nome que não deveria passar pela boca. O nome de Deus não deve passar pela boca, trata-se de uma palavra que é simplesmente suprimida do registro da língua, apagada do uso.

Benveniste compara tal interdição ao tabu, uma vez que há uma ambivalência também em torno da blasfemia: trata-se de uma proibição imposta de fora e, como o tabu, refreia o desejo do homem. No caso da blasfemia, a proibição refreia $o$ desejo do homem de profanar o sagrado, o nome de Deus. Por essa razão, para caracterizar a blasfemia, assim como o juramento, o nome de Deus precisa aparecer. Como o tabu, deve continuar a existir enquanto interdito. Dessa forma, pode ser entendida como um juramento de ultraje, pois, assim como ocorre no juramento, toma Deus por testemunha.

$\mathrm{O}$ autor lembra que as características do ato da blasfemia liga-se a um certo número de condições que se devem cumprir sucessivamente. A principal delas diz respeito à própria forma $\mathrm{da}$ expressão blasfêmica. Como se trata da expressão de uma emoção, ela tem sua própria sintaxe, a qual se aproxima da sintaxe das interjeições, realizando-se como uma exclamação. O autor faz referência à blasfemia como "uma palavra que se deixa escapar" (1969/1989a, p. 261). Certamente, não se trata de uma palavra comunicativa, mas somente expressiva, ainda que tenha um sentido. Além disso, a fórmula pronunciada não se refere a nenhuma situação em particular, mas exprime a intensidade de uma reação às circunstâncias. Não se refere ao $t u$ ou à terceira pessoa, nem abre um diálogo. $\mathrm{E}$, por incrível que pareça, a presença de um interlocutor nem mesmo é necessária. Isso porque a blasfemia faz com que o falante aja como se estivesse se traindo. Por isso, Benveniste nomeia a reação blasfêmica como uma descarga emotiva. Uma "descarga emotiva que se realiza em fórmulas fixas, inteligíveis e descritíveis" (p. 261).

A forma de base é a exclamação "nome de Deus", "sagrado nome de Deus". Em alguns casos, a intenção ultrajante pode ser acentuada com a substituição do nome pelo nome de um órgão do corpo, ou reduplicando a expressão, ou, ainda, invocando o anti-Deus, o diabo. Manifesta-se, assim, a necessidade, dissimulada no inconsciente, de transgredir o interdito. Realizando-se a transgressão, surge a censura, advinda das forças coercitivas que marcam a vida do homem na sociedade, na vivência de elementos culturais. Por essa razão, a blasfemia suscita uma eufemia, a qual tem o poder de corrigir a expressão e a desarmar enquanto imprecação. 
Segundo o autor, a eufemia conserva o quadro locucional da blasfemia, mas introduz modificações que na língua francesa podem se revelar de três espécies: a primeira é a substituição do nome de Deus por um outro nome inocente, como "Mon chapeau!"; a segunda é a mutilação do vocábulo Deus por aférese final, o que em francês produz a mudança de "par dieu!" para "pardi!". E a terceira é a criação de uma forma non-sense no lugar da expressão blasfêmica, como ocorre em francês: par le sang de Dieu!" que se transforma em "palsambleu!". Lembro aqui um exemplo comum desse formato na língua inglesa, o qual ocorre quando o falante pronuncia "My gosh!" ao invés de "My god?". Exemplos de eufemia com o nome de Deus em língua portuguesa não são comuns, mas o fenômeno pode ser visto ao se refrear a pronúncia de outros xingamentos, também interditados pela pressão das forças e sistemas culturais, como é o caso dos palavrões, cuja realização é apenas referida ao se dizer, em língua portuguesa, por exemplo: " $P u \ldots$. xa vida!".

Com a eufemia, assim, faz-se alusão a uma profanação de linguagem sem realizá-la, cumprindo sua função psíquica. Por essa razão, blasfemia e eufemia são vistas como atividades simétricas.

Com essa reflexão, retomo as principais ideias apresentadas no texto de Benveniste para, a partir dele, na sequência, refletir sobre dois aspectos que considero convocados na temática. Deles me ocupo na seção subsequente.

\section{Dois aspectos envolvidos}

Vejo na realização da eufemia, em especial, dois aspectos diretamente relacionados à relação do falante com a língua mobilizada no discurso. $\mathrm{O}$ primeiro deles diz respeito à ação de dizer. Trata-se do deslocamento do conteúdo do que é dito para o ato de dizer. É esse ato que está sujeito às sanções impostas pela cultura. $O$ falante mobiliza, na eufemia, aspectos da cultura que se marcam explicitamente em seu dizer, diferentemente de outras situações, em que tal explicitude não é verificada. Ao falar, o homem não apenas mobiliza formas e sentidos particulares explicitados na língua da qual se apropria, ele vai além, mobiliza, via determinados arranjos, valores sociais, capazes de revelar muito acerca da sua história construída no seio de uma sociedade e da experiência por ele vivida no mundo que o cerca. Em minha investigação, o conceito de cultura está relacionado ao sistema de valores, uma vez que na experiência da criança na linguagem se vê a realização vocal manifestar rudimentos da cultura, pois a criança entra no mundo do outro, o mundo do adulto, sai da liberdade da pura natureza para experienciar os limites simbólicos da cultura que a cerca. O saber linguístico, portanto, envolve a interdição advinda da cultura.

O segundo aspecto que quero enfocar é mais específico: diz respeito à possibilidade de tratamento linguístico dado pelo falante à blasfemia, caracterizando 
uma eufemia. $\mathrm{O}$ tratamento linguístico que burla o significante. A combinação de elementos in praesentia suscita a ocorrência de uma seleção. O signo assim encontra-se relacionado com outros signos ausentes. Na eufemia, a seleção de elementos linguísticos presentes no discurso tem o poder de evocar os elementos não ditos com tanta intensidade que são eles que constituem sentido. Diz-se sem dizer, numa relação metonímica em que os elementos postos lembram, de alguma forma, o não dito. A língua, neste caso, tem suas regras coercivas quebradas pela ação do falante que precisa marcar em suas escolhas linguísticas sua necessidade de interditar o profano, mas conservando sua existência, o que só é possível fazer negando o próprio dizer. $\mathrm{O}$ interdito, assim, passa a ser o enunciado dado, que se renova na ação da eufemia.

O tema debatido no texto de Benveniste coloca o homem falante/blasfemante em destaque, uma vez que no centro da questão encontra-se a descarga emotiva. O homem blasfemante é o responsável pelo ato de profanar o sagrado e o faz em sua relação com a língua. Evoca, nessa relação, a proibição posta na cultura e busca burlá-la por meio dos arranjos linguísticos. Trata-se de um tema, portanto, que permite pensar sobre a experiência humana na e pela linguagem. Ao fazer tal reflexão, desloco a questão para também ajudar a pensar na relação da criança com o interdito, tema que move todo este artigo, mas que recebe atenção específica na seção seguinte.

\section{A criança e o interdito}

O ser humano, ao nascer, vive sua primeira cisão: nasce na natureza, cumprindo uma função biológica, mas se constitui homem na cultura que o envolve, conforme é possível depreender do seguinte raciocínio:

Chamo cultura ao meio humano, tudo o que, do outro lado do cumprimento das funções biológicas, dá à vida e à atividade humanas forma, sentido e conteúdo. A cultura é inerente à sociedade dos homens, qualquer que seja o nível de civilização. Consiste numa multidão de noções e de prescrições, e também em interdições específicas, o que uma cultura proíbe a caracteriza ao menos tanto quanto aquilo que prescreve (BENVENISTE, 1963/2005, p. 31-32, grifo do autor).

Com essa concepção de cultura, o autor a vê como inteiramente simbólica, definida por representações complexas determinadas por valores como tradição, religião, leis, política, ética, artes:

[...] tudo isso que o homem, onde quer que nasça, será impregnado no mais profundo da sua consciência, e que dirigirá o seu comportamento em todas as formas da sua atividade (BENVENISTE, 1963/2005, p. 32).

Entre o homem, a língua e a cultura há um vínculo que se mantém no simbolismo articulador entre essas entidades, uma vez que a linguagem "manifesta e transmite" a cultura e "pela língua, o homem assimila a cultura, a perpetua ou a transforma" (BENVENISTE, 1963/2005, p. 32). Eis o entrelaçamento língua e cultura, constitutivo da inserção do homem na linguagem. 
Acerca do acesso ao mundo via linguagem, o autor apresenta a seguinte ideia:

Aquele que fala faz renascer pelo seu discurso o acontecimento e a sua experiência do acontecimento. Aquele que o ouve apreende primeiro o discurso e através desse discurso, 0 acontecimento reproduzido (BENVENISTE, 1963/2005, p. 26).

Eis aí para o autor a dupla função do ato de discurso: para o locutor, trata-se da representação da realidade; para o ouvinte, a recriação da realidade. Essa dupla função constitui a linguagem como fundamento da comunicação intersubjetiva. Tem-se indivíduo e sociedade como termos complementares, ou seja, graças à língua, a sociedade é possível e também o indivíduo, pois

O despertar da consciência na criança coincide sempre com a aprendizagem da linguagem, que a introduz pouco a pouco como indivíduo na sociedade (BENVENISTE, 1963/2005, p. 27).

$\mathrm{O}$ aspecto vocal, assim, define-se como elemento mediador entre aquele que fala e aquele que ouve. Nessa mediação, são mobilizados os valores culturais que a linguagem traduz, os quais são evocados na relação entre eu e tu. É a intersubjetividade constitutiva da linguagem que permite aos homens fundamentarem-se na própria linguagem.

Com base nesse princípio, entendo que há, portanto, uma experiência de aquisição da linguagem vivida pela criança, "uma experiência que vai a par, na criança, com a formação do símbolo e a construção do objeto" (BENVENISTE, 1963/2005, p. 31). E, nessa formação,
Benveniste reconhece o papel do adulto, uma vez que é no mundo do adulto, na sociedade dos homens que a criança viverá sua experiência na linguagem. Essa experiência é marcada pelo simbólico da linguagem, por meio do qual a cultura deixa seus traços impressos na língua, da qual cada homem se apropria para viver suas experiências de significação com outros via discurso. Por isso, a interpretação do sentido se dá sempre no seio de uma cultura, a partir dos traços reveladores de valores impressos na língua, os quais podem ser resgatados a partir da observação dos diferentes empregos possíveis da língua e que revelam o semantismo social a que Benveniste se referiu, o qual entendo como resultado das relações entre sistema interpretante, a língua, e sistema interpretado, a cultura e seus esquemas sociais.

Em minha tese (2015) já lembrei que em Estruturalismo e Linguística, Benveniste (1968/1989) diz que o aprendizado de uma língua, por parte da criança, não é resultado de uma faculdade natural, pois, na verdade, o que uma criança aprende quando aprende uma língua é o "mundo dos homens". E por mundo dos homens o linguista entende todos os dados que a linguagem traduz, e isso se dá no seio da cultura: quando o homem enuncia, o faz de forma a imprimir à sua língua valores culturais. Assim,

o que a criança adquire, aprendendo, como se diz, a falar, é o mundo no qual ela vive na realidade, que a linguagem lhe dá e sobre o qual ela aprende a agir (BENVENISTE, 1968/1989, p. 24). 
É possível entender, então, com base nessa afirmação, que a linguagem dá à criança um mundo. Se há convicção em relação a isso isso, mais um hiato vivido pelo homem é revelado: para assumir sua existência no mundo, ele precisa apreender esse mundo via linguagem. Para tanto, desloca-se na cultura, já que a apreensão de uma língua não é faculdade natural. $\mathrm{E}$ é nesse mundo dado que o homem aprenderá a agir, a partir do acesso garantido pela língua convertida em discurso.

É por meio da percepção dos sons da língua que o homem entra na linguagem e, consequentemente, nos dados que ela traduz no seio da cultura, uma vez que é ela, a linguagem, "a atividade significante por excelência" (BENVENISTE, 1966/1989, p. 223). Ou seja, ao mobilizar os elementos vocais da língua em palavras, o locutor mobiliza um conjunto de valores que marcam o mundo à sua volta. $\mathrm{E}$, ao fazê-lo, imprime à emissão vocal as particularidades advindas da sua constituição como homem nesse meio cultural.

Ocorre o fenômeno descrito por Benveniste como aquele que

[...] torna a experiência interior de um sujeito acessível a outro numa expressão articulada e representativa, e não por meio de um sinal como um grito modulado; realiza-se numa determinada língua (BENVENISTE, 1963/2005, p. 30).

É a intersubjetividade mobilizadora do que Benveniste entende como um sistema simbólico especial, constituído pela materialidade dos elementos vocais, emitidos pela mediação do aparelho vocal e percebidos pela mediação do aparelho auditivo; e pela imaterialidade dos significados evocados. Essa singularidade da emissão vocal traz o traço do humano à linguagem articulada pelo homem, uma vez que a realização vocal encontra a palavra; na natureza, a relação é outra: estando a palavra ausente, os animais não saem nunca da pura voz da natureza, comum à espécie inteira. O homem, segundo Benveniste (1963/2005, p. 29), "inventa e compreende símbolos", desde muito cedo, quando ainda criança, o que o distingue do animal, o qual nunca chega a essa capacidade.

É, portanto, nessa vivência inventiva e compreensiva das relações significantes que marcam sua cultura, que a criança se vê frente às interdições do seu próprio dizer, como atestam os dados que analiso na sequência.

\section{Os fatos observados}

Trago à luz da análise, inicialmente, um fato enunciativo apresentado por Silva (2009):

\section{Fato enunciativo 1}

Episódio: Franciele (1;8.10)

Situação: Franciele usava a expressão de xingamento "droga" sempre que algo não dava certo em suas brincadeiras, $o$ que a mãe seguidamente a repreendia. Certo dia, a criança estava brincando com a mãe perto e algo deu errado em sua brincadeira. Então Franciele disse:

*FRA: dó ...

*MÃE: Franciele [!]

*com: a mãe repreende.

*FRA: doguinha. (= droguinha) 
Em relação à transcrição, Silva (2009) explica que: "O dado de Franciele foi obtido a partir de um relato de sua mãe. Na transcrição, adotamos a seguinte convenção FRA= Franciele; *com=comentário do transcritor; [!]= ênfase". Ao apresentar esse fato, Silva (2009) deixa clara a relação da criança e do outro, no caso dessa situação, o adulto, a qual se caracteriza pelo poder cerceador assumido pelo adulto frente à palavra de xingamento da criança. A criança realiza nessa situação, mediante a censura da mãe, que, certamente, ecoa elementos de uma cultura marcada por determinada convenção social e caracterizada por sistemas culturais vigentes, a eufemia proposta por Benveniste. Afirmo isso porque vejo nesse ato da criança a realização dos dois aspectos anteriormente focalizados: o ato em si do dizer e não o seu conteúdo, ou seja, à criança interessa xingar, realizando o que Benveniste chama de "descarga emotiva", sem direcionar tal xingamento a um outro, no entanto, a enunciação da mãe funciona como a censura ao xingamento em si, numa clara relação de interpretância da língua e do esquema cultural que evoca uma imaterialidade de sentidos revelada no como dizer ou mesmo no não dizer, já que se trata de uma interdição. A vivência dessa relação de interpretância da língua leva a criança a realizar o segundo aspecto que focalizo: a eufemia que burla o significante e "diz sem dizer". Ao truncar a realização vocal da palavra "droga" e, via mobilização do sufixo "inha", a criança diz sem dizer, realizando o que foi afirmado anteriormente, uma relação metonímica em que os elementos postos lembram, de alguma forma, o não dito.

$\mathrm{Na}$ sequência, analiso outro fato enunciativo, este do corpus com o qual trabalho em meu projeto $A$ experiência da criança na linguagem:

\section{Fato enunciativo 2}

Situação: Dália (2;2;15) e o amigo mais velho (9 anos) disputam um brinquedo. Dália: é meu. Você é bob/

Mãe: DÁLIA!É feio xingar o coleguinha.

Dália: bobuuu bobuuu bobuuu

Comentários: Dália diz isso cantarolando e fazendo cócegas no amigo.

É importante dizer que as regras de transcrição deste fato enunciativo encontram-se explicitadas em Diedrich (2015): letras maiúsculas são usadas para tons ascendentes, a repetição de vogais indica alongamentos, a trilha comentário apresenta descrições advindas do olhar do transcritor.
Esse fato enunciativo se assemelha ao anterior, uma vez que a interdição também nesse caso advém do dizer da mãe em relação ao dizer da criança. A diferença, no entanto, está na maneira como essa criança lida com essa interdição e produz a eufemia. Nesse caso em específico, ela o faz por meio de um modo 
particular de mobilizar o aspecto vocal da enunciação, ou seja, usa arranjos musicados para envolver o significante de valores advindos de outros esquemas culturais que não o daquele relacionado ao xingamento. Essa mobilização permite dizer que a criança percebe, desde cedo, que, na língua, alguns sons assumem estatuto diferenciado em relação a outros. Isso só é possível a partir da vivência de situações enunciativas, por meio das quais a língua é tomada como objeto de interpretância, na relação de emissão e de percepção dos arranjos vocais.

\section{Considerações finais}

A reflexão que apresento aqui é inicial e necessita, sem dúvida alguma, ser aprofundada em trabalhos futuros. No entanto, acredito ser possível, com esse raciocínio, compreender mais sobre a natureza do homem e da linguagem, em especial, pelo fato de se estar pesquisando a linguagem da criança. Ao investigar o caráter de interdição que advém dos esquemas culturais nos quais a criança se vê inserida e que se marca no dizer do outro, percebo que a criança realiza, permanentemente, o movimento que vai: a) do geral da cultura para o particular da sua experiência social, b) do geral da língua para a particularidade de seu discurso.

O fenômeno apontado por Benveniste (1969/1989a) como "eufemia" realiza-se, assim, pela criança como forma de par- ticularizar seu dizer em relação ao tu e em relação à cultura que a cerca, via arranjos singulares da língua-discurso.

\section{L'enfant et sa relation avec l'interdiction : la mobilisation des arrangements discursifs particuliers}

\section{Résumé}

Cet article réfléchit sur le caractère de linterdiction qui marque la relation du locuteur avec la langue. Cette situation implique les concepts de culture et société. Un déplacement de thématique que Benveniste a exploité dans son texte La blasphèmie et l'euphèmie est fait dans le text pour discuter comme l'enfant vit cette relation d'interdiction depuis très jeune et il trouve manières de gérer la langue, pendant son expérience. Ces manières s'exprime au moyen de arrangements particuliers dans le discours.

Mots-clés : Interdiction. Expérience de l'enfant. Arrangements.

\section{Referências}

BENVENISTE, Émile. (1963). Vista d'olhos sobre o desenvolvimento da linguística. In: Problemas de Lingüística Geral I. Campinas: Pontes, 2005. p.19-33. . (1966). A forma e o sentido na linguagem. In: . Problemas de Linguística Geral II. Campinas: Pontes, 1989. p. 220-242. . (1968). Estruturalismo e linguística. In:___ Problemas de Linguística Geral II. Campinas: Pontes, 1989. p.11-28. 
. (1969). A blasfemia e a eufemia.

In:___ (1974). Problemas de Linguística

Geral II. Campinas: Pontes, 1989a. p. 259262.

- (1969). Semiologia da língua. In:__ (1974). Problemas de Linguística Geral II. Campinas: Pontes, 1989b. p. 43-67.

DIEDRICH, Marlete Sandra. Aquisição da linguagem: o aspecto vocal da enunciação na experiência da criança na linguagem (Tese de Doutorado). 2015. Programa de Pós-Graduação em Letras. Universidade Federal do Rio Grande Do Sul, Porto Alegre.

. (2017). O homem na linguagem: o entrelaçamento língua e cultura na aquisição da linguagem numa perspectiva enunciativa aquisicional. Acta Scientiarum: Language and Culture. Maringá, v. 39, n. 4, p. 381-386, Oct.-Dec., 2017.

FLORES, Valdir do Nascimento. Saussure e Benveniste no Brasil. Quatro aulas na École Normale Supérieure. São Paulo, Parábola Editorial, 2017.

SILVA, Carmem Luci da Costa. A criança na linguagem: enunciação e aquisição. Campinas, SP: Pontes, 2009. 